\title{
ISENÇÕES TRIBUTÁRIAS NOS MUNICÍPIOS BRASILEIROS: A INICIATIVA PARLAMENTAR E A NECESSIDADE DE ESTUDOS PRÉVIOS DE IMPACTO ECONÔMICO-ORÇAMENTÁRIO
}

\author{
Guilherme Aparecido da Rocha* \\ José Eduardo Costa Devides*
}

RESUMO: O presente artigo analisa a compatibilidade das leis de iniciativa parlamentar que instituem isenções tributárias em face da Constituição da República de 1988 e da Lei de Responsabilidade Fiscal, no contexto de crise econômica. Em conclusão, observou-se o risco de consequências prejudiciais ao Estado se não for enfrentado o problema da legalidade das leis tributárias de iniciativa parlamentar. O método de abordagem utilizado na pesquisa foi o dialético jurídico, notadamente à confrontação dos modelos econômicos de John Maynard Keynes e Friedrich Hayek em relação ao Estado brasileiro, paralelamente ao método de pesquisa bibliográfico.

Palavras-chave: Isenção tributária; Iniciativa parlamentar; Constitucionalidade; Legalidade; Economia.

\section{TAX EXEMPTIONS IN BRAZILIAN MUNICIPALITIES: THE PARLIAMENTARY INITIATIVE AND THE NEED FOR PREVIOUS STUDIES OF ECONOMIC-BUDGETARY IMPACT}

\begin{abstract}
This article analyzes the compatibility of the parliamentary initiative laws that institute tax exemptions in the face of the 1988 Constitution and the Fiscal Responsibility Law, in the context of economic crisis. In conclusion, the risk of damaging consequences to the State has been observed if the problem of the legality of the parliamentary tax laws is not addressed. The method of approach used in the research was the juridical dialectic, notably the confrontation of the economic models of John Maynard Keynes and Friedrich Hayek in relation to the Brazilian State, parallel to the method of bibliographic research.
\end{abstract}

Keywords: Tax exemption; Parliamentary initiative; Constitutionality; Legality; Economy.

\footnotetext{
* Professor das faculdades Galileu (Botucatu-SP) e Gran Tietê (Barra Bonita-SP). Procurador Geral da Câmara Municipal de Jaú-SP. Mestre em Direito pela Universidade de Marília - UNIMAR. E-mail: guilhermejau@gmail.com

* Advogado. Agente de controle interno da Câmara Municipal de Jaú-SP. Mestre em Direito pela Universidade de Marília - UNIMAR. E-mail: du.devides@gmail.com
} 


\section{INTRODUÇÃO}

Em tempos de crise várias são as alternativas cogitadas pelo Estado em vista do seu papel de interventor e regulador da economia. Dentre elas as isenções tributárias são sempre cogitadas como instrumentos ao seu enfrentamento, especialmente no modelo propugnado por John Maynard Keynes - ao menos no Brasil.

Há, contudo, um problema atual e complexo relacionado às isenções que pode provocar distorções, não apenas na economia, mas também no orçamento do Estado. Trata-se da possibilidade de serem instituídas a partir de leis de iniciativa parlamentar, ocorrência que, embora possa ser consumada em qualquer ente federativo, tem maior relevância em âmbito municipal, o que justifica a realização de um corte metodológico que enfatiza estes entes federativos em vista das peculiaridades que os caracterizam - como a proximidade entre eleitos e eleitores.

Em face disso, mostra-se imprescindível analisar a legitimidade parlamentar para iniciar o processo legislativo tendente à criação de isenções tributárias, sob o prisma constitucional e legal - especialmente em relação à Lei de Responsabilidade Fiscal.

Se no passado a legitimidade à criação de isenções tributárias era interpretada como sendo privativa do chefe do Poder Executivo, hoje os Tribunais - inclusive o Supremo Tribunal Federal - mantém entendimento firme no sentido de concluir pela ampla legitimidade à apresentação de projetos de lei dessa natureza a partir de iniciativa parlamentar, o que se faz (acertadamente) com arrimo no texto constitucional.

Não obstante, há uma tese sustentada pelos que se opõe à legitimidade parlamentar para iniciar o processo legislativo tendente a criar isenções tributárias que precisa ser mais cuidadosamente analisada. Isso porque ela tem com plano de fundo o (fundado) receio sobre as consequências que a aprovação desenfreada de isenções pode gerar no orçamento público.

Nesse contexto, constata-se que a questão da compatibilidade das leis de iniciativa parlamentar que instituem isenções tributárias com a Lei de Responsabilidade Fiscal não tem sido adequadamente analisada pelos Tribunais. É isto que justifica este trabalho, cujo objetivo é identificar a compatibilidade das referidas leis com a ordem constitucional, e, principalmente, com a ordem legal - especificamente, com a Lei de Responsabilidade Fiscal. 
O método de abordagem utilizado na pesquisa foi o dialético jurídico, notadamente para o confronto entre os modelos econômicos de John Maynard Keynes e Friedrich Hayek em vista da Constituição brasileira de 1988, paralelamente aos métodos de pesquisa bibliográfico e documental, inclusive com recurso a projetos de lei apresentados em diferentes Municípios brasileiros.

\section{A CRIAÇÃO DE ISENÇÕES TRIBUTÁRIAS A PARTIR DE LEIS DE INICIATIVA PARLAMENTAR}

Se a possibilidade de novas isenções tributárias serem criadas a partir de leis propostas pelo chefe do Poder Executivo é inquestionável perante a doutrina e a jurisprudência brasileira, o mesmo não pode ser dito em relação às leis de iniciativa parlamentar que visem idêntico objetivo.

Dessa forma, para que se possa analisar adequadamente a razão da divergência sobre a legitimidade parlamentar para criar isenções tributárias é fundamental compreender a estrutura do sistema normativo nacional sobre Direito Tributário, especificamente em relação às isenções tributárias.

A criação de qualquer isenção tributária demanda, por essência, a utilização da lei. Acerca desta assertiva não há dúvida, haja vista a clareza do artigo 97, inciso VI, do Código Tributário Nacional, que prevê: "somente a lei pode estabelecer: [...] VI - as hipóteses de exclusão, suspensão e extinção de créditos tributários, ou de dispensa ou redução de penalidades."

A isenção tributária opera a exclusão do crédito tributário, consoante artigo 175 do Código Tributário Nacional, que prevê: “excluem o crédito tributário: I - a isenção”.

Portanto, a combinação dos dispositivos - 97, VI e 175, I - não deixa dúvida acerca da necessidade de lei para criação de isenções tributárias. Muitas dúvidas pairam, contudo, em relação aos legitimados constitucionais para deflagrar o respectivo processo legislativo.

Durante muito tempo perdurou o entendimento segundo o qual competia apenas ao chefe do Poder Executivo a iniciativa das leis destinadas à criação de incentivos tributários, especialmente em relação às isenções. Em outras palavras, admitiu-se durante considerável 
período que apenas Prefeitos, Governadores e o Presidente da República eram legitimados para iniciar o processo legislativo tendente à criação de isenções tributárias.

Não obstante, não faltaram tentativas de instituir isenções tributárias a partir de leis de iniciativa parlamentar. Muitas delas, após serem aprovadas foram judicialmente questionadas, mediante sistema de controle concentrado. $\mathrm{O}$ resultado de muitos julgados referendou, durante muito tempo, que competia somente ao Poder Executivo a iniciativa de leis dessa natureza, conforme exemplo a seguir:

AÇÃO DIRETA DE INCONSTITUCIONALIDADE. LEI COMPLEMENTAR 171/08, DO MUNICÍPIO DE ZUZANO. ALTERA A REDAÇÃO E ACRESCENTA § ÚNICO AO ART. 207 DA LEI COMPLEMENTAR 39/07, ISENTANDO DO IPTU OS CONTRIBUINTES APOSENTADOS, PENSIONISTAS OU BENEFICIÁRIOS DA PRESTAÇÃO CONTINUADA QUE ATENDAM A DETERMINADOS REQUISITOS. LEI DE INICIATIVA DE VEREADOR. VIOLAÇÃO AO PRINCÍPIO DA INDEPENDÊNCIA ENTRE OS PODERES. ATRIBUIÇÃO EXCLUSIVA DO PREFEITO. INCONSTITUCIONALIDADE DECLARADA. PEDIDO JULGADO PROCEDENTE (SÃO PAULO, 2010).

O ponto comum dos julgados que concluem pela inconstitucionalidade das leis parlamentares que instituem isenções tributárias é a violação do princípio da separação das funções ${ }^{1}$.

Com frequência, também se alega - nas petições das ações diretas de inconstitucionalidade impetradas - violação ao $\S 1^{\circ}$ do artigo 61 da Constituição da República, que prevê:

Art. 61. A iniciativa das leis complementares e ordinárias cabe a qualquer membro ou Comissão da Câmara dos Deputados, do Senado Federal ou do Congresso Nacional, ao Presidente da República, ao Supremo Tribunal Federal, aos Tribunais Superiores, ao Procurador-

\footnotetext{
1 No mesmo sentido: AÇÃO DIRETA DE INCONSTITUCIONALIDADE. VÍCIODE INICIATIVA. Lei municipal de autoria demembro do Poder Legislativo que dispõe sobrea concessão de isenção de IPTU aos imóveislocados ou cedidos para fins de funcionamentode entidades assistenciais ou religiosas.Matéria que é de iniciativa do PoderExecutivo. Ofensa aos arts. 5, "caput", daCESP e art. $2^{\circ}$ da CF/88. Caracterização devício de iniciativa. Inconstitucionalidadeformal subjetiva. Ação julgada procedente (SÃO PAULO, 2011).
} 
Geral da República e aos cidadãos, na forma e nos casos previstos nesta Constituição.

$\S 1^{\circ}$ São de iniciativa privativa do Presidente da República as leis que: [...]

b) organização administrativa e judiciária, matéria tributária e orçamentária, serviços públicos e pessoal da administração dos Territórios. (grifo nosso)

Mas com a evolução do tema constatou-se que o $\S 1^{\circ}$ do artigo 61 da Constituição da República é imprestável a retirar do Poder Legislativo a iniciativa das leis tributárias, porque ele se refere apenas aos Territórios Federais, conforme jurisprudência pacífica do Supremo Tribunal Federal:

AGRAVO REGIMENTAL NO RECURSO EXTRAORDINÁRIO.
TRIBUTÁRIO. INSTAURAÇÃO DO PROCESSO LEGISLATIVO.
MATÉRIA TRIBUTÁRIA. INICIATIVA PARLAMENTAR.
VALIDADE. INVOCAÇÃO DO ART. 61, § $1^{\circ}$, II, B, DA
CONSTITUIÇÃO FEDERAL. IMPOSSIBILIDADE. AGRAVO
IMPROVIDO. I - A Constituição de 1988 não veda a iniciativa do
Poder Legislativo em legislar sobre matéria tributária. Precedentes. II -
Impossibilidade da invocação do art. 61, § $1^{\circ}$, II, b, da CF, uma vez que
esse dispositivo constitucional tem sua aplicação restrita ao processo
legislativo no âmbito dos territórios federais. III - Agravo regimental
improvido (BRASIL, 2011).

Outra tese que ocupa a questão na tentativa de justificar a impossibilidade de uma isenção tributária ser criada a partir de iniciativa parlamentar é a que sustenta a repercussão orçamentária da questão, a qual supostamente geraria lesão aos artigos 165 e 166 da Constituição da República. De todas, esta efetivamente é a melhor tese de repulsa à legitimidade parlamentar. Ela encontra amparo na doutrina de CARRAZA (2009, p. 319):

Em matéria tributária, porém, prevalece, a respeito, o art. 61: a iniciativa das leis tributárias - exceção feita à iniciativa das leis tributárias dos Territórios (que, no momento, não existem), que continua privativa do Presidente da República, ex vi do art. 61, § $1^{\circ}$, II, "b”, in fine, da CF - é ampla, cabendo, pois, a qualquer membro do Legislativo, ao chefe do Executivo, aos cidadãos etc.

Este raciocínio vale para as leis que criam ou aumentam tributos. Não para as leis tributárias benéficas, que continuam a ser de iniciativa privativa do chefe do Executivo (Presidente, Governador ou Prefeito). 


\begin{abstract}
Abrindo um rápido parêntese, entendemos por leis tributárias "benéficas” as que, quando aplicadas, acarretam diminuição de receita (leis que concedem isenções tributárias, que parcelam débitos fiscais, que aumentam prazos para o normal recolhimento de tributos etc.). No mais das vezes, favorecem aos contribuintes.

Ora, só o chefe do Executivo - senhor do Erário e de suas conveniências - reúne condições objetivas para aquilatar os efeitos que, leis deste tipo, produzirão nas finanças públicas sob sua guarda e superior responsabilidade. Assim, nada pode ser alterado, nesta matéria, sem sua prévia anuência.

Chegamos a esta conclusão analisando os dispositivos constitucionais que tratam das finanças públicas, especialmente os arts. 165 e 166 da Lei Maior, que dão ao chefe do Executivo a iniciativa das leis que estabelecem orçamentos anuais.
\end{abstract}

A preocupação que se apresenta como elemento fundamental à compreensão de Carraza é a consequência da renúncia fiscal operada em decorrência dos benefícios fiscais. Essa tese é utilizada pelo Tribunal de Justiça do Estado de Minas Gerais ${ }^{2}$, que assim já decidiu sobre o tema:

Ação Direta de Inconstitucionalidade de leis municipais. Lei Orgânica do Município de Campina Verde. Dispositivo que concede adicional por tempo de serviço. Constitucionalidade. Autonomia municipal. Lei Municipal 01/2004. Isenção de IPTU para determinadas categoria de contribuintes. Leis tributárias benéficas. Reflexos no orçamento. Iniciativa exclusiva do Executivo. Inconstitucionalidade declarada. Representação acolhida em parte. - Determinados direitos aplicáveis aos servidores públicos, como é o caso dos adicionais por tempo de serviço, possuem índole tipicamente constitucional, pelo que sua inclusão em lei de organização municipal, à qual se atribui natureza jurídica relativamente equiparável à constitucional, não configura usurpação da reserva de iniciativa delineada no art. $61, \S 1^{\circ}$, 'c', da Constituição Federal e no art. 66, III, 'b' e 'c', da Constituição Estadual. - A iniciativa das leis tributárias - exceção feita à iniciativa das leis tributárias dos Territórios (que, no momento, não existem), que continua privativa do Presidente da República, 'ex vi' do art. $61, \S 1^{\circ}$, II, 'b', in fine, da CF - é ampla, cabendo, pois, a qualquer membro do Legislativo, ao Chefe do Executivo, aos cidadãos, etc. Este raciocínio vale para as leis que criam ou aumentam tributos. Não para as leis

\footnotetext{
2 Tanto que há reprodução literal da obra de CARRAZA na ementa do acórdão, embora não inserida a referência bibliográfica pertinente.
} 
tributárias benéficas, que continuam a ser de iniciativa privativa do Chefe do Executivo (MINAS GERAIS, 2009).

Contudo, a questão já foi exaustivamente abordada pelo Supremo Tribunal Federal, ainda que exclusivamente sob o prisma constitucional. Nestes casos, o STF firmou entendimento que não vislumbra ofensa - nas leis de inciativa parlamentar sobre isenções tributárias - à reserva de iniciava do Executivo às leis orçamentárias, mas mera repercussão secundária. Para a Suprema Corte brasileira, a melhor interpretação da questão é a seguinte:

AGRAVO DE INSTRUMENTO. CONSTITUCIONAL E TRIBUTÁRIO. INICIATIVA LEGISLATIVA. MATÉRIA TRIBUTÁRIA. CONCORRÊNCIA ENTRE PODER LEGISLATIVO E PODER EXECUTIVO. LEI QUE CONCEDE ISENÇÃO. POSSIBILIDADE AINDA QUE O TEMA VENHA A REPERCUTIR NO ORÇAMENTO MUNICIPAL. AGRAVO E RECURSO EXTRAORDINÁRIO PROVIDOS.

1. [...]

2. O recurso extraordinário é cabível contra acórdão que julga constitucionalidade in abstracto de leis em face da Constituição Estadual, quando for o caso de observância ao princípio da simetria. Precedente:Rcl 383, Tribunal Pleno, Rel. Min. Moreira Alves.

3. A iniciativa para início do processo legislativo em matéria tributária pertence concorrentemente ao Poder Legislativo e ao Poder Executivo (art. 61, § 1º, II, “b”, da CF). Precedentes:ADI 724-MC, Tribunal Pleno, Rel. Min. Celso de Mello, DJ de 15.05.92; RE 590.697-ED, Primeira Turma, Rel. Min. Ricardo Lewandowski, Dje de 06.09.2011; RE 362.573-AgR, Segunda Turma, Rel. Min. Eros Grau, Dje de 17.08.2007).

4. In casu, o Tribunal de origem entendeu pela inconstitucionalidade formal de lei em matéria tributária por entender que a matéria estaria adstrita à iniciativa privativa do Chefe do Poder Executivo, dada a eventual repercussão da referida lei no orçamento municipal.

5. Agravo de instrumento provido.

6. Recurso extraordinário provido (BRASIL, 2013). (grifo nosso)

Não obstante o afastamento das teses que visam recusar legitimidade ao Poder Legislativo para deflagrar projetos de lei destinados à criação de isenções tributárias, há um ponto revelado pela última delas - de lesão aos artigos 165 e 166 da Constituição - que não pode ser desprezado. Precisamente, se está a falar da repercussão orçamentária da isenção criada. 
Se o Poder Legislativo pode criar uma isenção tributária, é imprescindível que o faça ao amparo de fontes seguras. Ao questionar a legitimidade dos parlamentares, Roque A. Carraza se preocupa, em última análise, com a repercussão da isenção criada por um Poder que não goza da estrutura do Poder Executivo para proceder aos estudos necessários à sua criação.

A questão é de alta relevância e atualidade, notadamente no período atual - de crise estrutural e conjuntural -, que coloca as isenções tributárias constantemente na ordem do dia como possíveis instrumentos de auxílio à recuperação da economia nacional. No entanto, antes de abordar a necessidade - por parte do Poder Legislativo - de prévios estudos à criação de isenções tributárias, é fundamental adentrar à análise dos impactos econômicos dos incentivos fiscais, que podem contribuir à superação da crise, mas também podem comprometer gravemente o orçamento público.

\section{OS IMPACTOS ECONÔMICOS DECORRENTES DOS INCENTIVOS FISCAIS}

Os tributos não servem apenas à atividade de arrecadação de receitas. Prestam-se, também, à relevante função de intervenção no domínio econômico, que ocorre por meio da extrafiscalidade e a qual integra o tripé das funções dos tributos nacionais - ao lado da fiscalidade e da parafiscalidade.

Segundo Geraldo Ataliba, a extrafiscalidade ocorre mediante o "emprego deliberado do instrumento tributário para finalidades não financeiras, mas regulatórias de comportamentos sociais, em matéria econômica, social e política” (1966, p. 151).

O tributo extrafiscal objetiva arrecadar recursos ao erário, porém esta finalidade não lhe é precípua. A arrecadação é um efeito subjacente ao seu núcleo, que visa à intervenção do Estado na economia, mediante o fomento ou o desestímulo de determinados setores.

O ordenamento jurídico brasileiro está repleto de exemplos de tributos cuja principal finalidade é a intervenção econômica. Para conferir-lhes efetividade, a Constituição os excepcionou da obediência de alguns princípios, como o da anterioridade, o da noventena e até mesmo do princípio da legalidade, o que se conclui pela exegese do $\S 1^{\circ}$ do artigo 150 , bem como do $\S 1^{\circ}$ do artigo 153, ambos da Constituição da República de 1988.

Mas em verdade, qualquer tributo pode ser utilizado para, de algum modo, fomentar ou coibir comportamentos, de acordo com as políticas fiscais adotadas pelos diferentes entes 
federativos brasileiros. Isenções tributárias conferidas em relação ao imposto sobre a propriedade predial e territorial urbano (que representa a principal fonte de receita tributária de muitos municípios brasileiros), por exemplo, podem estimular a instalação de novas indústrias ou até mesmo a migração de novas famílias.

O que não se pode perder de vista, em hipótese alguma, é a ratio que leva à utilização do tributo como mecanismo de intervenção e regulação de comportamentos. Para isso, o Estado deve observar fielmente os objetivos fundamentais da República, previstos no artigo $3^{\circ}$ da Constituição:

Art. $3^{\circ}$ Constituem objetivos fundamentais da República Federativa do Brasil:

I - construir uma sociedade livre, justa e solidária;

II - garantir o desenvolvimento nacional;

III - erradicar a pobreza e a marginalização e reduzir as desigualdades sociais e regionais;

IV - promover o bem de todos, sem preconceitos de origem, raça, sexo, cor, idade e quaisquer outras formas de discriminação.

Essas são as balizas que devem fundamentar a utilização dos tributos pelos entes federativos. Nesse sentido, os princípios que norteiam o ordenamento devem estar respeitados, não se admitindo violações de nenhuma ordem, independente do período enfrentado. Ao versar sobre incentivos fiscais em tempos de crise, Assunção assim discorre:

As exações e desonerações tributárias, desse modo, se colocamcomo ferramentas para o incentivo ou coibição de condutas por parte dosdestinatários normativos, contribuindo para a realização - ou até realizandodiretamente - finalidades propugnadas pela Constituição Federal. Quandoas exonerações são utilizadas para incentivar condutas que promovema efetivação de objetivos constitucionais, com impactos no seio social,justifica-se a extrafiscalidade. São esses objetivos e finalidades, em síntese, que legitimam a intervenção estatal (2011, p. 103).

A intervenção estatal legítima, portanto, é a que utiliza a extrafiscalidade tributária tendo como norte o alcance das finalidades constitucionais. De se ressaltar, aliás, que o Supremo Tribunal Federal já decidiu que a possibilidade de intervenção do Estado na economia 
“não exonera o Poder Público do dever jurídico de respeitar os postulados que emergem do ordenamento constitucional brasileiro” (BRASIL, 1997).

A tarefa de conciliar Economia e Direito, no entanto, é das mais complexas. Sabe-se que a isenção tributária é instrumento de intervenção econômica que serve ao socorro do contribuinte - e da economia, evidentemente -, especialmente em períodos de crise. Mas diante do que se expôs, fica hialino que a sua utilização deve visar ao preenchimento das finalidades constitucionais.

A isenção tributária foi uma das ferramentas que auxiliaram o Brasil a enfrentar as dificuldades econômicas de 2008, que ameaçaram fortemente a estabilidade do país e cujos reflexos ainda podem ser sentidos (OLIVEIRA, 2013).

No curso de uma crise econômica, a experiência demonstrou que o Estado não pode ser mero espectador. A mão invisível não se mostra uma solução infalível, que permite a inércia da ação estatal, diferente do que foi imaginado outrora ${ }^{3}$. Como exemplo da falibilidade deste modelo pode-secitar a grande depressão de 1930, que exigiu a intervenção do Estado para ser superada.

Nesse contexto, o “problema no alternador” a que Keynes se referira por ocasião da crise de 1930 e que Krugman faz menção é, exatamente, a indicação de que "o motor da economia não daria a partida por conta própria” (2009, p. 105), o que demandava auxílio público. Em outras palavras, é fundamental que o Estado intervenha para viabilizar a superação da crise e a retomada do crescimento.

Uma das formas de auxílio público - em tempos de crise - é o benefício fiscal. Foi esta uma das soluções que os Estados Unidos tentaram utilizar para a crise de 2008, mas que restou infrutífera (KRUGMAN, 2009). Nos Estados Unidos, a razão apontada para o insucesso foi a quantidade do estímulo ofertado, que foi insuficiente, bem como porque boa parte do dinheiro reduzido não foi gasta, mas poupada (KRUGMAN, 2009).

Não obstante o insucesso nos Estados Unidos, Krugman aponta elementos que precisam ser considerados pelo governo para viabilizar o êxito dos benefícios fiscais no

\footnotetext{
${ }^{3}$ Nesse sentido é a teoria de Adam Smith, que se apoia na existência de "leis da natureza" ou na "divina providência" - chamado de "mão invisível” pelo autor e que tendia a resolver e guiar os problemas econômicos e sociais (HUNT, 2005).
} 
processo de enfretamento da crise. Dentre eles se destaca o aumento na quantidade dos incentivos concedidos, bem como a celeridade em aprová-los (KRUGMAN, 2009).

No Brasil o período excessivo de utilização das isenções tributárias, talvez em virtude de razões políticas que se sobrepuseram às econômicas, é apontado como uma das razões do insucesso da sua utilização (ANDERSON, 2003), ao menos se analisado o cenário a médio e longo prazo.

Em qualquer caso, o conteúdo do processo de criação da isenção, seja sob o prisma qualitativo ou quantitativo, é de fundamental relevância ao seu sucesso. Cada benefício criado deve ser resultado de profunda análise ${ }^{4}$, que revele os aspectos benéficos esperados, bem como os possíveis prejuízos decorrentes da redução do montante arrecadatório.

Evidente, assim, que não se desconsidera a relevância da utilização de isenções tributárias pelo Estado, notadamente em períodos de crise. É por essa razão que não é possível enxergar na política econômica proposta pelo modelo de FriedrichHayek a solução para a questão brasileira.

A austeridade proposta por Hayek, como a adotada no modelo inglês de Margareth Thatcher - na qual se implantou uma redução da carga tributária apenas sobre altos rendimentos, em desprezo de outros setores (ANDERSON, 2003) - não se compatibiliza com as finalidades da Constituição da República de 1988.

O modelo de austeridade do governo Thatcher pode ser apontado, a partir de diferentes prismas, como contrário aos objetivos fundamentais na Constituição brasileira, haja vista que objetiva a criação de níveis massivos de desemprego, a repressão das greves, a imposição de uma severa legislação anti-sindical e o corte drástico de gastos sociais (ANDERSON, 2003).

Ademais, não se vislumbra compatibilidade entre a ratio motivadora da redução da carga tributária incidente somente sobre altos rendimentos, em detrimento de outros setores. Agir dessa maneira, prima face, contraria os objetivos fundamentais da República brasileira.

A isenção tributária demanda um rigoroso cuidado do Estado para evitar que a distorção gerada não prejudique o sistema econômico, mais do que auxiliá-lo, bem como para

\footnotetext{
${ }^{4}$ A deficiência neste processo é que resultou na insuficiência dos benefícios concedidos pelos Estados Unidos durante a crise de 2008. Segundo Krugman, o primeiro pacote de benefícios fiscais correspondeu a 1\% do PIB dos EUA, enquanto o segundo subiu a montante correspondente a aproximadamente 4\% do PIB (2009). Ou seja, uma elevação quádrupla que se tivesse sido aplicada $a b$ initio teria acelerado o processo de superação da crise.
} 
que efetivamente sirva à superação da crise. Não pode, nesse contexto, ser criada como fruto de paixões ou de meros pedidos de determinados setores.

Toda intenção de se criar uma isenção tributária deve ser desenvolvida à luz de profunda análise técnica, que permita avaliar a curto, médio e longo prazo qual será o impacto gerado e em vista de qual objetivo. Após o processo de análise, o projeto deve ser apresentado somente se houver compatibilidade com as finalidades constitucionais e sem lesão aos princípios que sustentam o Estado brasileiro.

Ao abordar o contexto em análise, Assunção conclui que:

\begin{abstract}
A análise da legitimidade da concessão de benefícios fiscais fundamenta-se na verificação das finalidades da medida, e na sua pertinência com relação aos valores refletidos no texto constitucional. Será legítimo o incentivo fiscal concedido sob o amparo de desígnios constitucionais, como instrumento de promoção de finalidades relevantes à coletividade. Por via transversa, será ilegítimo (e, portanto, odioso) o benefício que se destinar a privilegiar pessoas ou situações específicas, em detrimento do princípio da igualdade; ou que não guarde pertinência com os objetivos constitucionais autorizadores da intervenção do Estado sobre a economia (2011, p. 108).
\end{abstract}

É nesse contexto que a pesquisa sobre a qualidade dos estudos de impacto econômicoorçamentário que instruem leis criadoras de isenções tributárias deve avançar, especialmente em relação aos Municípios brasileiros e em vista da legitimidade parlamentar à criação desses benefícios tributários.

\title{
3. A REALIDADE MUNICIPAL BRASILEIRA E AS ISENÇÕES TRIBUTÁRIAS: A IMPRESCINDIBILIDADE DE ESTUDOS DE IMPACTO ECONÔMICO
}

Em muitos Municípios brasileiros as isenções tributárias ainda são tratadas como benefícios sem contrapartida, ou seja, sem ônus a nenhuma das partes. Isenções são discutidas e votadas como se não implicassem restrições orçamentárias e consequências econômicas maléficas ao interesse local, o que se faz mediante o enaltecimento exclusivo dos aspectos positivos que elas revelam. 
Altamente preocupados com a opinião pública, os legisladores tendem à inclinação favorável às novas isenções, notadamente as que dispensam o pagamento de tributos em contrapartida à tutela do meio ambiente ou de uma condição humana específica (como o acometido de determinada doença ou a simples aposentadoria, v.g.), especialmente em virtude do bônus político que elas costumam gerar.

Nesse contexto, a defesa da tese da inconstitucionalidade das leis de iniciativa parlamentar que instituem isenções tributárias - em virtude da repercussão orçamentária que geram - nada mais é que mera decorrência de um - fundado - receio sobre as consequências práticas de um - eventual - grande número de isenções incidentes sobre o orçamento público. Justificar a impossibilidade de se deflagrar o processo legislativo pelos legisladores em questões orçamentárias -artigos 165 e 166 da Constituição da República - somente reforça o exposto.

Ao fundamentar a tese da exclusividade do Executivo para iniciar o processo legislativo em matéria de benefícios fiscais, Roque A. Carrazza assim discorre:

Ora, só o Executivo tem condições de avaliar a repercussão financeira de "isenções, anistias, remissões, subsídios e benefícios de natureza financeira, tributária e creditícia”.

Não faz sentido, vênia concessa, exigir que o Executivo faça o demonstrativo, sobre as receitas e despesas, de benefícios fiscais que ele não previu, nem sabe quando e em que dimensões surgirão. É o caso, inclusive, de invocarmos, neste passo, a vetusta parêmia ad impossibilita nemo tenetur (2009, p. 320). (grifo do autor)

Os aspectos salientados pelo mencionado autor são muito importantes e precisam ser cuidadosamente analisados. O primeiro atine à avalição da repercussão financeira dos benefícios fiscais. Impossível discordar sobre a necessidade de que ela seja realizada. Mas impossível concordar que somente o Executivo possa realizá-la, haja vista que toda análise, modificações, discussões e aprovação das leis orçamentárias é feita pelo Poder Legislativo, nos termos do artigo 166 da Constituição da República, que dentre outras disposições, prevê:

Art. 166. Os projetos de lei relativos ao plano plurianual, às diretrizes orçamentárias, ao orçamento anual e aos créditos adicionais serão apreciados pelas duas Casas do Congresso Nacional, na forma do regimento comum. 
$\S 1^{\circ}$ Caberá a uma Comissão mista permanente de Senadores e Deputados:

I - examinar e emitir parecer sobre os projetos referidos neste artigo e sobre as contas apresentadas anualmente pelo Presidente da República; II - examinar e emitir parecer sobre os planos e programas nacionais, regionais e setoriais previstos nesta Constituição e exercer o acompanhamento e a fiscalização orçamentária, sem prejuízo da atuação das demais comissões do Congresso Nacional e de suas Casas, criadas de acordo com o art. 58.

$\S 2^{\circ}$ As emendas serão apresentadas na Comissão mista, que sobre elas emitirá parecer, e apreciadas, na forma regimental, pelo Plenário das duas Casas do Congresso Nacional.

$[\ldots]$

A Constituição não possui texto despido de sentido. Se a Constituinte outorgou ao Legislativo a missão de legislar sobre orçamento - permitindo-lhe a aplicação de alterações - é porque se conhecia a capacidade deste poder em executar o referido mandamento.

No trecho citado acima, Carrazza também salienta a ausência de sentido na imposição de que o Executivo considere benefícios fiscais na sua atividade de prever receitas e fixar despesas. Aqui surge um ponto crítico do problema. Se por um lado a discordância é patente, haja vista que é evidente o dever do Executivo produzir as leis orçamentárias com base nas isenções tributárias criadas - ainda que provenientes de leis de iniciativa parlamentar -, por outro a questão aventada pelo autor demanda aprofundada análise.

Ao ser aprovada uma isenção tributária a partir de uma lei de iniciativa parlamentar, a partir de quando ela incidirá? A resposta a esta questão depende da análise sobre o conteúdo da lei. Mais do que isso, depende da análise da legislação orçamentária em vigência. A depender das constatações feitas, a isenção incidirá somente a posteriori, ou, mais precisamente, depois que for regularmente considerada na estimativa de receitas da lei orçamentária - providência que poderá ser realizada apenas no exercício financeiro subsequente ao da sua aprovação.

A repercussão de uma isenção tributária no orçamento do Município não pode, em hipótese alguma, ser desprezada pelo parlamentar que cria um projeto pretendendo a sua instituição ou majoração. Se o Supremo Tribunal Federal reconhece a ausência de inconstitucionalidade na medida, o mesmo não pode ser dito no âmbito infraconstitucional. Especificamente, no âmbito da Lei de Responsabilidade Fiscal, que prevê: 
Art. 14. A concessão ou ampliação de incentivo ou benefício de natureza tributária da qual decorra renúncia de receita deverá estar acompanhada de estimativa do impacto orçamentário-financeiro no exercício em que deva iniciar sua vigência e nos dois seguintes, atender ao disposto na lei de diretrizes orçamentárias e a pelo menos uma das seguintes condições:

I - demonstração pelo proponente de que a renúncia foi considerada na estimativa de receita da lei orçamentária, na forma do art. 12, e de que não afetará as metas de resultados fiscais previstas no anexo próprio da lei de diretrizes orçamentárias;

II - estar acompanhada de medidas de compensação, no período mencionado no caput, por meio do aumento de receita, proveniente da elevação de alíquotas, ampliação da base de cálculo, majoração ou criação de tributo ou contribuição.

$\S 1^{\circ}$ A renúncia compreende anistia, remissão, subsídio, crédito presumido, concessão de isenção em caráter não geral, alteração de alíquota ou modificação de base de cálculo que implique redução discriminada de tributos ou contribuições, e outros benefícios que correspondam a tratamento diferenciado.

$\S 2^{\circ}$ Se o ato de concessão ou ampliação do incentivo ou benefício de que trata o caput deste artigo decorrer da condição contida no inciso II, o benefício só entrará em vigor quando implementadas as medidas referidas no mencionado inciso.

$\S 3^{\circ} \mathrm{O}$ disposto neste artigo não se aplica:

I - às alterações das alíquotas dos impostos previstos nos incisos I, II, IV e V do art. 153 da Constituição, na forma do seu $\S 1^{\circ}$;

II - ao cancelamento de débito cujo montante seja inferior ao dos respectivos custos de cobrança.

A criação de uma isenção tributária a partir de uma lei de iniciativa parlamentar não permite a irresponsabilidade. Em outras palavras, não permite que ela seja criada sem a obediência aos ditames (do art. 14) da Lei de Responsabilidade Fiscal, pois neste caso embora ela possa ser classificada como constitucional, será concomitantemente acometida de vício de ilegalidade.

Se o parlamentar pretende a criação de uma isenção tributária, está dotado de legitimidade constitucional a fazê-la. Não pode, contudo, atuar movido a paixões, nem divorciado da responsabilidade fiscal.

A inserção de uma isenção tributária no mercado pode distorcê-lo. Pode atentar à livre concorrência, em virtude de um benefício criado em desrespeito ao princípio da igualdade, por exemplo. É por isso que o projeto de lei que pretende criá-la deve estar apoiado em forte lastro 
técnico, pois somente desta forma os demais legisladores poderão avaliar sobre a legalidade e a conveniência da medida.

A isenção tributária também pode impactar intensa e negativamente o erário, que sofrerá queda arrecadatória. Por isso, o projeto de lei deve ser claro ao especificar as previsões de queda nas arrecadações, bem como - se for o caso - as medidas de compensação a serem adotadas. O parlamentar que pretende isentar alguém do pagamento de um tributo tem o dever de indicar quem pagará pela isenção. Por exemplo: se um projeto pretende isentar proprietários idosos do pagamento de IPTU, deve indicar quem pagará tributos com alíquotas mais elevadas para compensar a medida.

É conveniente apresentar um projeto que carrega uma isenção tributária sem indicar os prejuízos que ela gerará - ao erário ou aos que suportarão aumento dos tributos como medida de compensação. Mas ao ter que apresentar também quem suportará o ônus da isenção, se insere a parcela de responsabilidade inerente à atividade de representação popular - que até o momento não tem sido analisada pelos Tribunais, conforme pode ser constatado abaixo:

AÇÃO DIRETA DE INCONSTITUCIONALIDADE. LEI MUNICIPAL DE LONDRINA N. 9.765/05. NORMA DE ISENÇÃO DE IPTU. CRITÉRIOS DEFINIDOS NA LEI. NATUREZA TRIBUTÁRIA E NÃO ORÇAMENTÁRIA. INOCORRÊNCIA DE INCONSTITUCIONALIDADE FORMAL POR VÍCIO DE INICIATIVA (ART. 133, II/III CE/PR). OFENSA A LEI DE RESPONSABILIDADE FISCAL - AUSÊNCIA DE ESTUDO DE IMPACTO ORÇAMENTÁRIO-FINANCEIRO IRRELEVÂNCIA. BASE DE CÁLCULO É O VALOR VENAL DO IMÓVEL INDEPENDENTEMENTE DAS EDIFICAÇÕES NESTE CONTIDAS. VALOR ARBITRADO PELO MUNICÍPIO. AÇÃO IMPROCEDENTE (PARANÁ, 2010). (grifo nosso)

Com a (acertada) admissão judicial de projetos de lei que criam isenções tributárias a partir de iniciativa parlamentar, a discussão que ganha relevo e deve ser desenvolvida a partir de agora se ampara na imprescindibilidade dos estudos econômicos-orçamentários que lastreiem a respectiva propositura.

Não se questiona que o tema - sobre a obediência à Lei de Responsabilidade Fiscal é infralegal e não deve ser enfrentado perante o sistema de controle concentrado de constitucionalidade. Mas isso não significa que a análise econômica e orçamentária deva ser 
desprezada. Concluir nesse sentido é um equívoco grave, que a médio e longo prazo, levará o Brasil a um aguçamento da crise atual.

Nesse contexto, ousamos discordar de Martins, para quem seria possível dispensar o estudo de prévio impacto orçamentário-financeiros nos casos de criação de isenções tributárias para novas áreas municipais - como distritos industriais recentemente implantados, por exemplo. Segundo o nobre autor,

[...] todo o estímulo fiscal cuja concessão possa provocar um impacto negativo no orçamento, com possível redução de receitas, deve ser submetido a todos os severos controles que a Constituição e a lei orçamentária impõem. Não aqueles cujo impacto é nenhum, visto que sua concessão não reduz receitas - no futuro aumenta-las-á - não tem reflexo, não afeta o orçamento, não gera qualquer despesa não programada (2010, p. 23/24). (grifo nosso)

A razão da discordância em relação ao posicionamento apresentado é clara. Implantado novo setor industrial é evidente que os empresários que instalarem estabelecimentos no local deixarão de recolher tributos - cujos respectivos créditos estarão excluídos em virtude de lei municipal -, o que por si só justifica a exigência das providências prévias previstas no artigo 14 da Lei de Responsabilidade Fiscal.

Não há como dispensar o pagamento de um tributo sem apresentar aos representantes do povo estudos detalhados do impacto que isso gerará no orçamento do Município. Primeiro, porque não se está dispensando um tributo inexistente, à medida que se está a versar sobre IPTU ou ISS, com regra. Segundo, porque não se pode desprezar que a isenção está sendo criada em relação a uma parte de empresários - que não abrange os que, no passado, instalaram seus estabelecimentos em outros distritos, ou em quaisquer outras zonas municipais.

Se é certo que a crise que alcança o Brasil tem caráter global, também é certo que fatores locais contribuem ao seu aguçamento ou à sua mitigação. Nesse sentido, aprovar isenções tributárias em larga escala e sem responsabilidade fiscal é algo que se pode classificar - por qualquer teoria econômica - como autodestrutivo.

O uso das isenções tributárias segundo o modelo proposto por Keynes é totalmente diverso da criação irresponsável. Se ao amparo de estudos especializados já é custosa e 
complexa a missão de superar crises - haja vista o exemplo dos Estados Unidos, em 2008 -, quiçá utilizá-las a esmo, como se tem visto em muitos Municípios brasileiros.

\section{CONCLUSÕES}

Ao final da presente pesquisa conclui-se que embora seja indiscutível a necessidade do uso da lei à criação das isenções tributárias, o mesmo não pode ser dito em relação a quem possui legitimidade para deflagrar o respectivo processo legislativo.

Se durante muito tempo perdurou o entendimento segundo o qual competia apenas ao Poder Executivo propor projetos de leis tendentes a instituir novas isenções tributárias, recentemente muitas decisões judiciais concluíram em sentido diverso. Precisamente, decidiram pela possibilidade de projetos dessa natureza ser apresentados por integrantes do Poder Legislativo.

Embora o Supremo Tribunal Federal tenha assentado jurisprudência conclusiva pela legitimidade parlamentar para iniciar o processo legislativo destinado à criação de isenções tributárias, há Tribunais que continuam a concluir contrariamente, o que é feito ao amparo da doutrina de Roque Antonio Carrazza, para quem a lei instituidora de benefício fiscal de qualquer natureza somente pode ser criada pelo chefe do Poder Executivo.

De todos os pontos salientados na doutrina de Carraza, há que se conferir destaque à preocupação que constitui o seu plano de fundo, que se refere à consequência orçamentária decorrente da aprovação desenfreada de isenções tributárias a partir de leis propostas por parlamentares.

Em tempos de crise, as isenções tributárias assumem função de protagonismo. Segundo Keynes, elas são fundamentais ao fomento de atividades que podem contribuir com o restabelecimento do crescimento econômico. Para isso, porém, precisam ser criadas a partir de profundo estudo técnico, para que não gerem prejuízos - ao mercado e ao Estado.

A teoria de Keynes, compatibilizada com a Constituição da República e com os objetivos fundamentais previstos no artigo $3^{\circ}$, não se importa com a paternidade da lei que institui uma isenção tributária. Se importa, apenas, com a adequação perfeita do benefício criado ao objetivo visado, que deve ser o de recuperar a economia e de devolver a estabilidade ao Estado. 
Diante disso, qualquer lei que não observe fielmente tais preceitos, positivados no ordenamento jurídico brasileiro por meio da Lei de Responsabilidade Fiscal, deve ser repelida. Se não for extirpada pelo controle concentrado de constitucionalidade, não pode deixar de sêla por meio de um controle de legalidade feito na base do Poder Judiciário, em relação a cada Município que eventualmente institua inadequadamente uma isenção tributária.

Compreender diversamente é atentar à ordem jurídica interna e à salubridade do sistema econômico brasileiro, que deve estar em constante compatibilidade com as finalidades previstas ao longo do texto constitucional de 1988.

\section{REFERÊNCIAS BIBLIOGRÁFICAS}

ANDERSON, Perry. Balanço do neoliberalismo. In: Pós-neoliberalismo: as políticas sociais e o Estado democrático. Org.: PABLO, Gentili; Emir, Sader. Rio de Janeiro: Paz e Terra, 2003.

ASSUNÇÃO, Matheus Carneiro. Incentivos fiscais em tempos de crise: impactos econômicos e reflexos financeiros. Revista da PGFN, v. 1, p. 99-121, 2011.

ATALIBA, Geraldo. Sistema Constitucional Tributário Brasileiro. São Paulo: Revista dos Tribunais, 1966.

BRASIL, Supremo Tribunal Federal. Agravo regimental no agravo de instrumento $\mathrm{n}^{\circ}$ 809719/MG. Relator: Min. Luiz Fux. Pesquisa de jurisprudência, Acórdãos, 26 abril 2013. Disponível em: <http://www.stf.jus.br/portal/jurisprudencia/pesquisarJurisprudencia.asp>. Acesso em: 13 mar. 2018.

Agravo Regimental no Recurso Extraordinário n. ${ }^{\circ}$ 640208. Relator: Ministro Ricardo Lewandowski. Pesquisa de jurisprudência, Acórdãos, 04 outubro 2011. Disponível em: $<$ http://www.stf.jus.br/portal/jurisprudencia/pesquisarJurisprudencia.asp>. Acesso em: 03 mar. 2018.

. Recurso Extraordinário n. ${ }^{\circ}$ 205193. Relator: Ministro Celso de Mello. Pesquisa de

jurisprudência, Acórdãos, $1997 . \quad$ Disponível em: <http://www.stf.jus.br/portal/jurisprudencia/pesquisarJurisprudencia.asp>. Acesso em: 06 mar. 2018.

. Recurso extraordinário no 640208/MG. Relator: Min. Ricardo Lewandowski. Pesquisa de jurisprudência, Acórdãos, 04 outubro 2011. Disponível em: $<$ http://www.stf.jus.br/portal/jurisprudencia/pesquisarJurisprudencia.asp>. Acesso em: 12 mar. 2018.

CARRAZZA, Roque Antonio. Curso de Direito Constitucional Tributário. 25. ed. São Paulo: Malheiros, 2009. 
HUNT, E. K. História do pensamento econômico. Trad.: José Ricardo Brandão Azevedo e Maria José Cyhlar Monteiro. Revisão técnica: André Villela. 2. ed. Rio de Janeiro: Elsevier, 2005.

KRUGMAN, Paul R.A crise de 2008 e a economia da depressão. Trad.: Afonso Celso da Cunha Serra. Rio de Janeiro: Elsevier, 2009.

MARTINS, Ives Gandra da Silva. Inteligência do artigo 14 da lei de responsabilidade fiscal (lei complementar n. 101/2000): estímulos sem impacto orçamentário não são pelo dispositivo abrangidos. Parecer de 01 de outubro de 2010. Disponível em: <http://www.gandramartins.com.br/parecer/detalhe/id/PA00468>. Acesso em: 10 nov. 2016.

MINAS GERAIS. Tribunal de Justiça. Ação Direta de Inconstitucionalidade n. ${ }^{\circ}$ 46830678.2007.8.13.0000. Relator: Desembargador Herculano Rodrigues. Pesquisa de jurisprudência, Acórdãos, 08 maio 2009. Disponível em: $<$ http://www.tjmg.jus.br/portal/jurisprudencia/consulta-de-jurisprudencia/acordaos/>. Acesso em: 13 mar. 2018.

OLIVEIRA, Edson Luciani de. Direito tributário e economia: análise conjunta para objetivos sociais sustentáveis. Revista do Mestrado em Direito da UCB, v. 7, n. ${ }^{\circ}$ 1, p. 62-91, 2013.

PARANÁ. Tribunal de Justiça. Ação direta de inconstitucionalidade n. ${ }^{\circ}$ 544229-3. Relator: Desembargador Miguel Pessoa. Pesquisa de jurisprudência, Acórdãos, 08 abril 2010. Disponível em: <http://portal.tjpr.jus.br/jurisprudencia/>. Acesso em: 22 mar. 2018.

SÃO PAULO. Tribunal de Justiça. Ação direta de inconstitucionalidade n. ${ }^{0} 0153012-$ 54.2011.8.26.0000. Relator: Desembargador Roberto Mac Cracken. Pesquisa de jurisprudência, Acórdãos, 23 novembro 2011. Disponível em: <https://esaj.tjsp.jus.br/cjsg/consultaCompleta.do>. Acesso em: 10 mar. 2018.

Tribunal de Justiça. Ação direta de inconstitucionalidade n. ${ }^{\circ}$ 177.980-0/9. Relator: Desembargador Armando Toledo. Pesquisa de jurisprudência, Acórdãos, 24 fevereiro 2010. Disponível em: <https://esaj.tjsp.jus.br/cjsg/consultaCompleta.do>. Acesso em: 10 mar. 2018. 